\title{
The Coastal Boundary Layer and Air Pollution - A High Temporal Resolution Analysis in the East Mediterranean Coast
}

\author{
Leenes Uzan ${ }^{*}, 1$ and Pinhas Alpert ${ }^{2}$ \\ ${ }^{1}$ Association of Towns for Environmental Protection (Sharon-Carmel) P.O.B 3041, Hadera, Israel \\ ${ }^{2}$ Department of Geophysics and Planetary Sciences, Tel Aviv University, Tel Aviv, 69978, Israel
}

\begin{abstract}
The East Mediterranean (EM) coast is characterized by warm sea temperatures and a nearly linear coastline. Both parameters influence the sea breeze front and the atmospheric conditions most relevant to air pollution dispersion. Here, the high resolution boundary-layer diurnal variation is highlighted leading to a distinct pattern of spatial-temporal air pollution dispersion, for over 25 years, from Israel's largest coal-fired power plant. Over 4,000 air pollution events were segregated by semi-objective synoptic systems and 7 years of boundary layer profiles carried out by acoustic radar. Results clarify why the highest air pollution events occur during summer at 12:00- 15:00 h through the average coincident drop of the boundary layer height down to $450 \mathrm{~m}$ above the ground. Here, the interaction between the synoptics and the sea-breezes is shown to play a significant role in the specific air pollution pattern.
\end{abstract}

Keywords: Coastal Boundary Layer, Lap3000, Sea Breeze front, air pollution.

\section{INTRODUCTION}

One of the most significant consequences of the acceleration in the world's urge for advancement is air pollution. In general, air pollution is a by-product of a combustion process dependent on the type of fuel burned, the combustion process and the meteorological conditions. Here, the effects of different synoptic systems and the associated boundary layer dynamics, on the severity of air pollution episodes from the largest power plant in Israel- the "Orot -Rabin" coal-fired power plant (ORPP) are investigated. The ORPP is situated along the flat terrain of the central coast of Israel, generating about 2,600 MW, and is monitored by an array of 17 air monitoring stations operated by the Association of Towns for Environmental Protection (ATEP) (Fig. 1). Although the ORPP produces electricity consecutively, with maximum generation during the summer and winter seasons, air pollution events from the ORPP are measured mainly during the summer days between 12:00-17:00 local standard time (LST). Furthermore, for over 25 years the ATEP has measured a distinct spatial and temporal pattern of the ground level air pollution dispersion emitted from the ORPP as follows. Beginning late morning (09:00 LST) the maximum is located northeast to the ORPP. Toward the afternoon (12:00-15:00 LST) an increase in air pollution concentration is measured at about $7 \mathrm{~km}$ east to the ORPP. Later on, an increase is measured southeast to the ORPP until evening hours (18:00 LST) (Fig. 2). The local meteorological conditions affecting the air pollution dispersion have been studied earlier [1-5]. Earlier studies, however, were based on a subjective classification of the synoptic systems and concluded with a number of meteorological prototypes that lead to ground level air

\footnotetext{
*Address correspondence to this author at the Association of Towns for Environmental Protection (Sharon-Carmel) P.O.B 3041, Hadera, Israel; Tel: 972-4 6123407; Fax: 972-4-6333448; E-mail: Leenes@igudhadera.co.il
}

pollution events. The aim of this research is to analyze the diurnal process of meteorological parameters of the atmospheric boundary layer, based on semi-objective synoptic classification and acoustic radar profiles, in the attempt to explain the spatial and temporal ORPP air pollution dispersion based on a very large number of airpollution events (about 4,200).

During the summer months, the EM upper air synoptic system is governed by a subtropical anticyclone, with the outcome of a nearly continuous inversion aloft [6-9]. The lower atmosphere is dominated by a Persian Trough causing a semipermanent large scale westerly flow over Israel [7-12]. The interaction of the large scale diurnal wind oscillation and the sea breeze (SB) is controlled by local meteorological conditions such as land-sea temperature difference, the large scale wind and the thermal convection [13-21]. Kalmikov [22] analyzed theoretically and quantitatively the hypothesis of the mesoscale coastal circulations predominance in the inversion generation. The results show that the inversion intensity generated by adiabatic mechanisms is an order of magnitude stronger in the mesoscale breeze circulations, compared to the common synoptic systems that govern the EM weather. On the large scale, Alpert and Leiman [13] investigated the Israeli planetary boundary layer (PBL) using a 3-D mesoscale numerical model in the conditions of a warm summer case. They have found that as the SB penetrates, the coastal PBL height drops by $50 \%$ from the altitude of $1200 \mathrm{~m}$ above ground level (AGL) at $08: 00 \mathrm{~h}$ to the height of $600 \mathrm{~m}$ AGL at 12:00 LST. This modeled PBL pattern was supported by our ATEP survey of the ORPP air pollution events since 1981 as concentrations rise with decrease of the PBL height. (Figs. 3, 4).

\section{MATERIALS AND METHODOLOGY}

In order to evaluate the main synoptic systems in which ORPP air pollution events occur, 4,248 air pollution events 

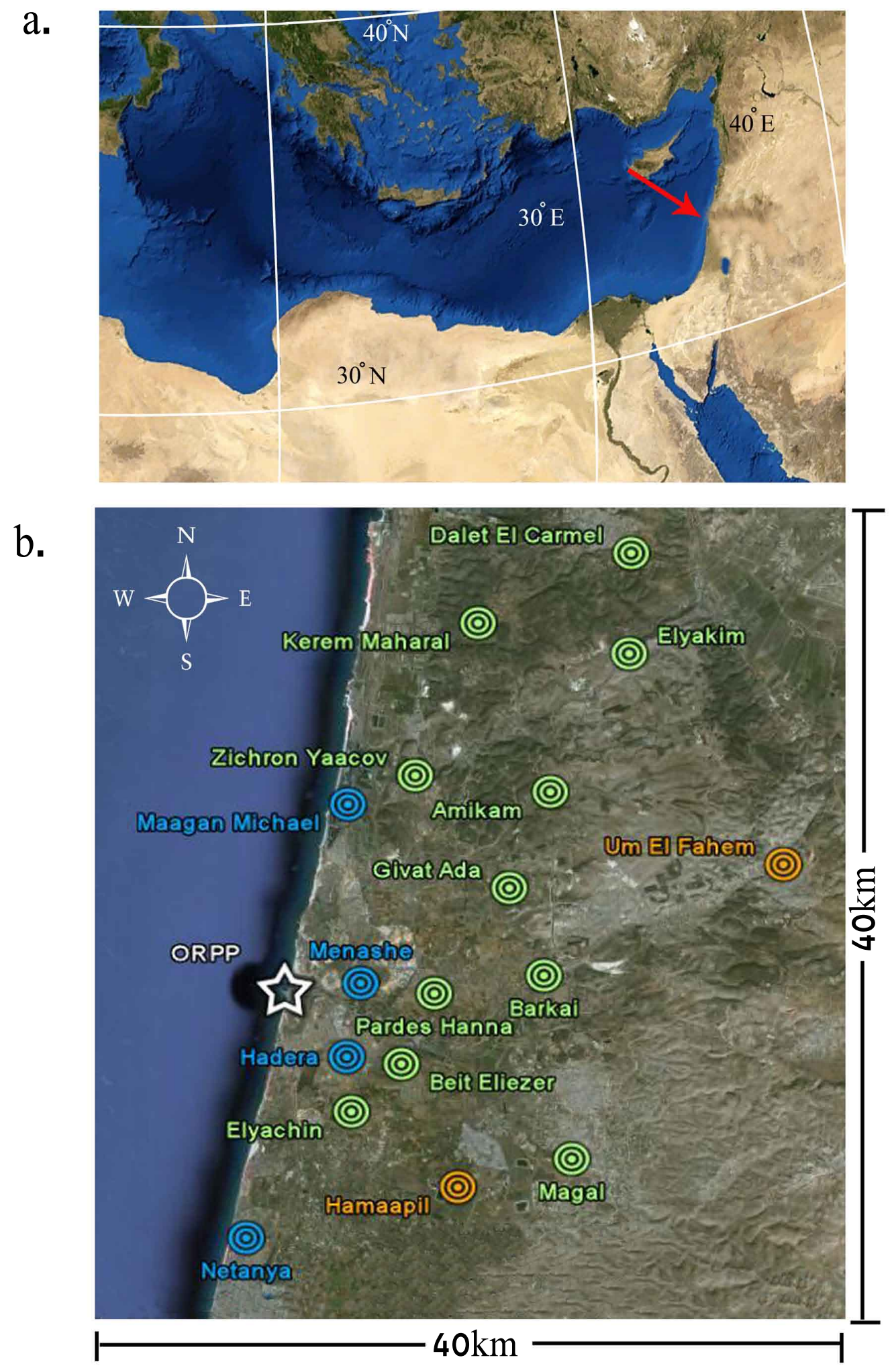

Fig. (1). A Google Earth map of the central coast of Israel (b) including the Orot-Rabin power plant (ORPP, 触) and 17 air monitoring stations surrounding it (@). Marked in blue are monitoring stations utilized to investigate the SBF entrance time (Sec.3). Marked in yellow are monitoring stations with solar radiation data (Sec.3). The panel above (a) is a NASA map where the general EM area is depicted ( $\sim 28$ $\left.40^{\circ} \mathrm{N}, 15-40^{\circ} \mathrm{E}\right)$. 
Sum of 5 min average $\mathrm{SO}_{2}$ concentration measured in 2006 by ATEP air monitoring stations

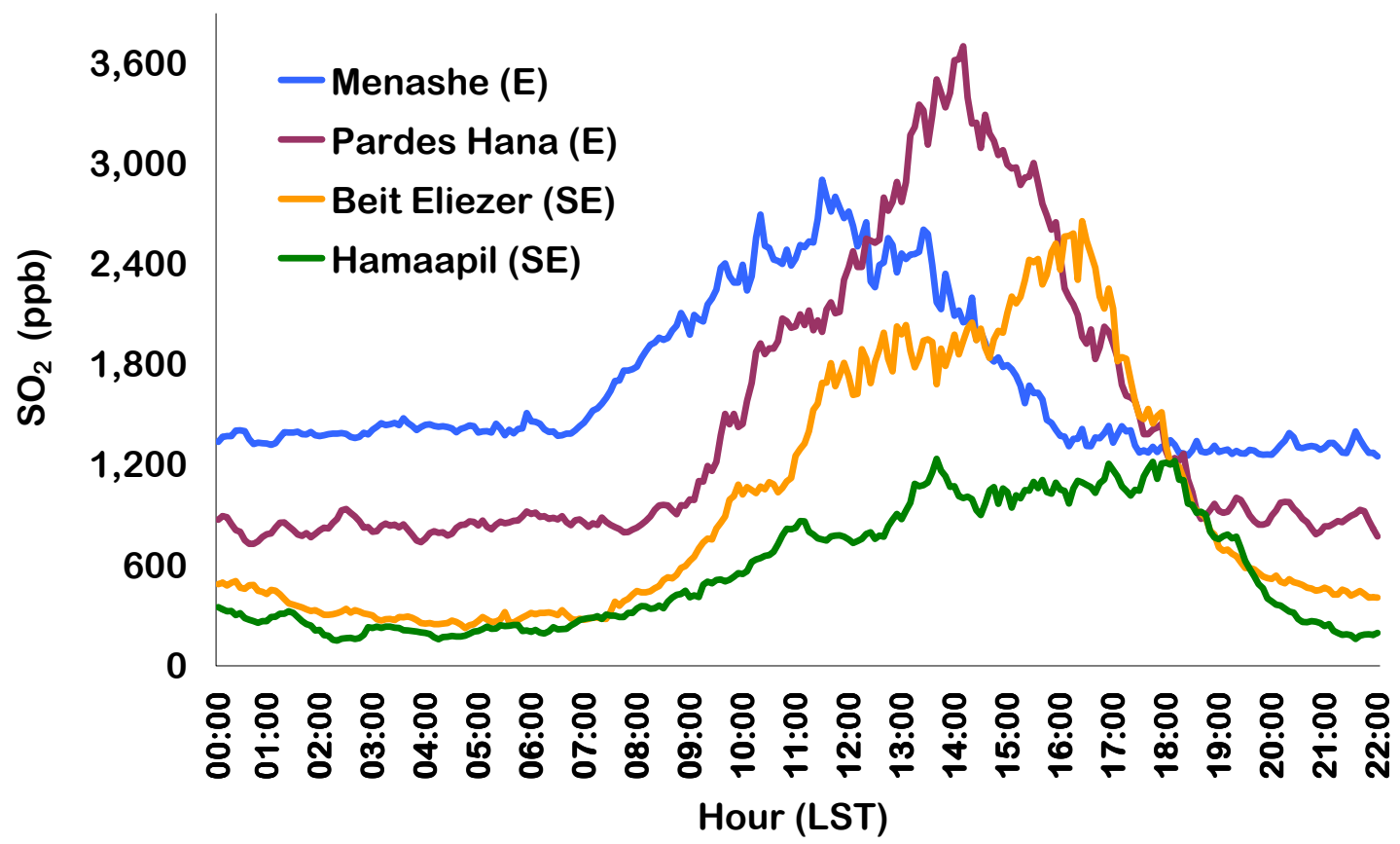

Fig. (2). $\mathrm{SO}_{2}$ averaged measurements (in ppb) during 2006 from four monitoring stations: Menashe, Pardes-Hana (both situated east -E- to the ORPP), Beit-Eliezer and Hamaapil, (both situated south east -SE- to the ORPP). These four stations are positioned close to the ORPP (Fig. 1). The numbers of the 2006 events, as defined in Sec. 2, were 48, 74, 27, 8, respectively. The percents of air pollution events originated from the ORPP were $98 \%, 96 \%, 63 \%$ and $100 \%$, respectively. In 2006 data availability of the monitoring stations was over $90 \%$.

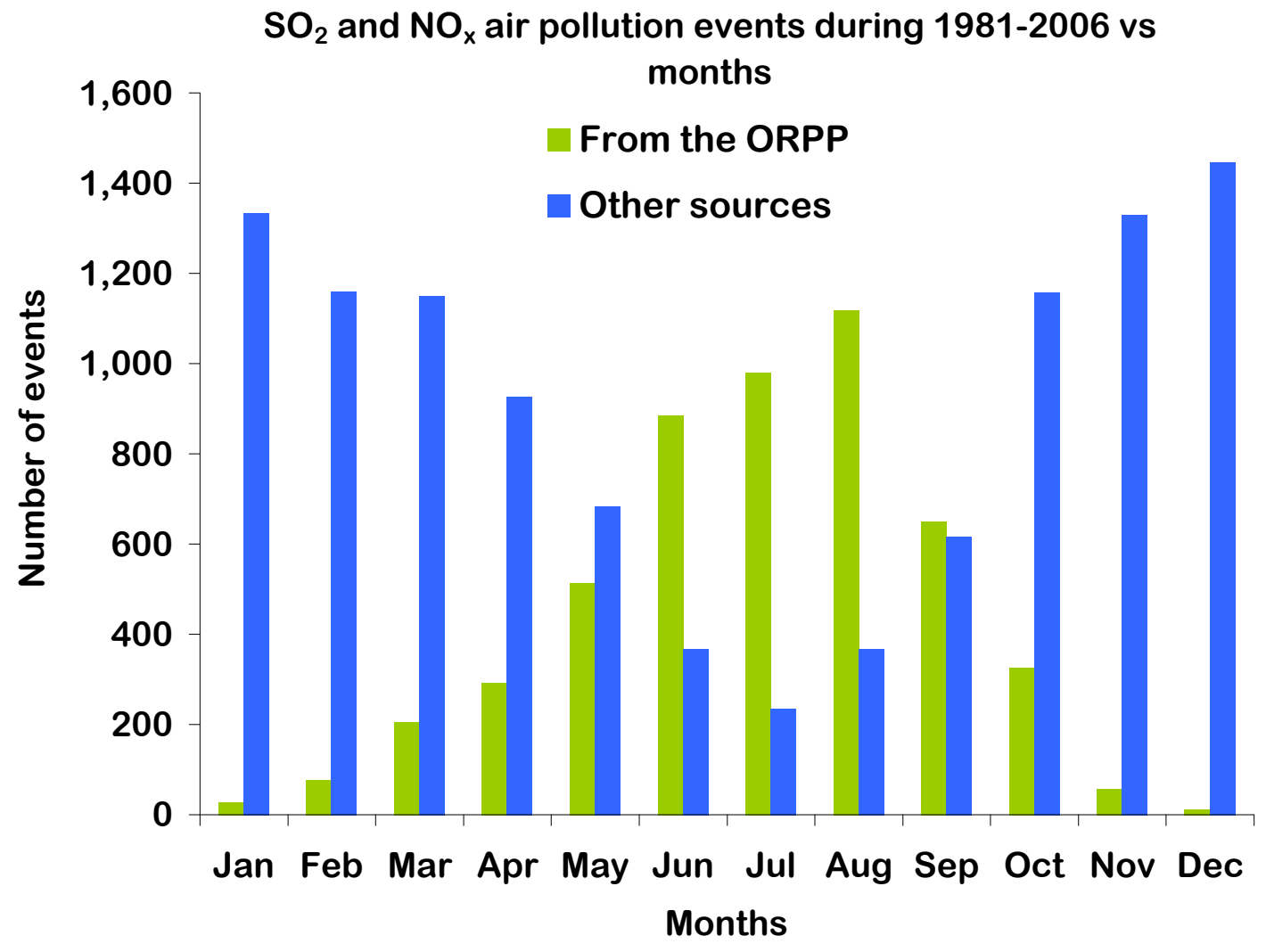

Fig. (3). 15,919 Air pollution events during 1981-2006 classified by source, ORPP (green bars) or other (blue bars) and by months. Definition of the sources was according to the criteria outlined in Sec. 2. 


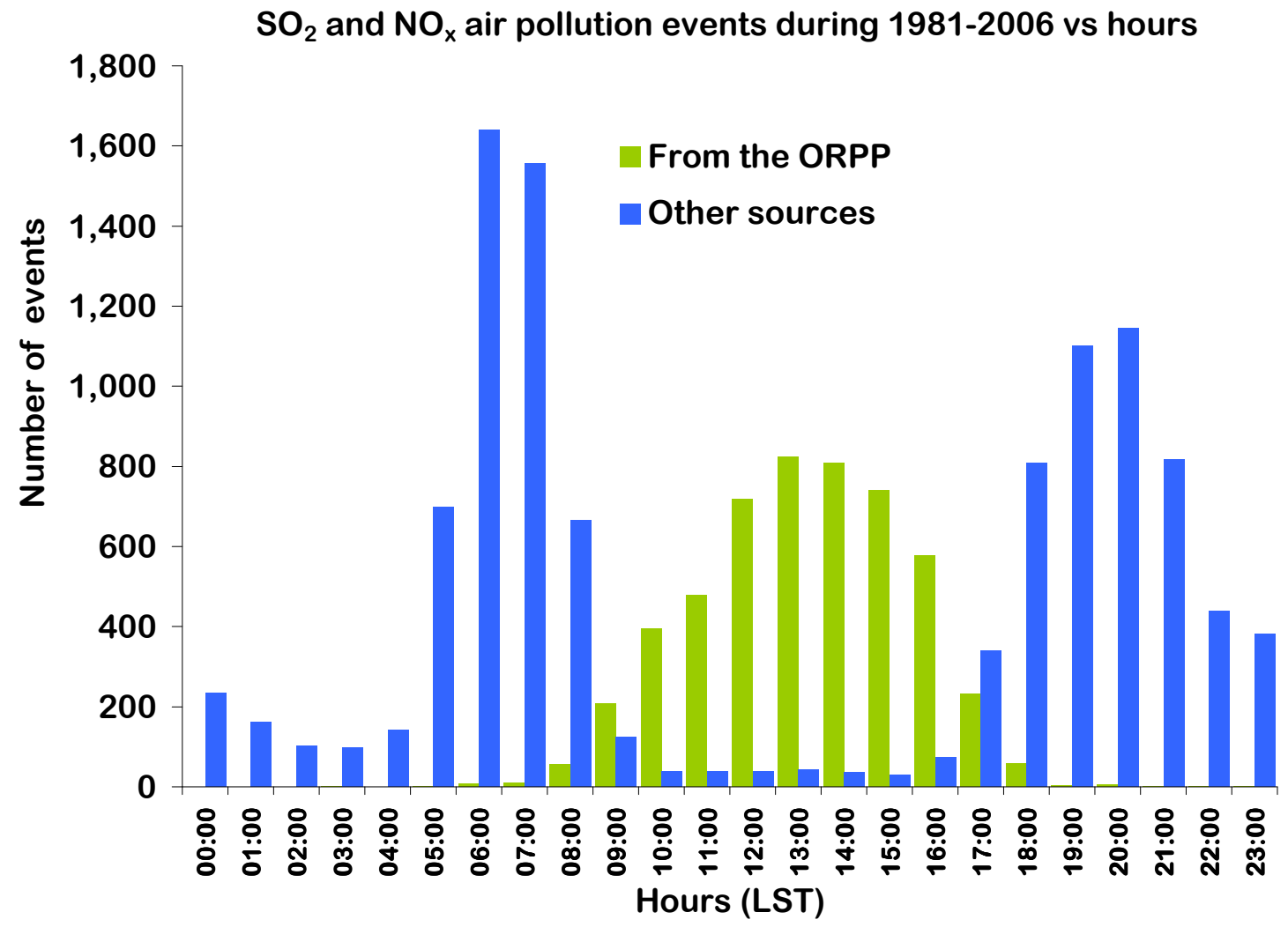

Fig. (4). As in Fig. (3) but for diurnal hour.

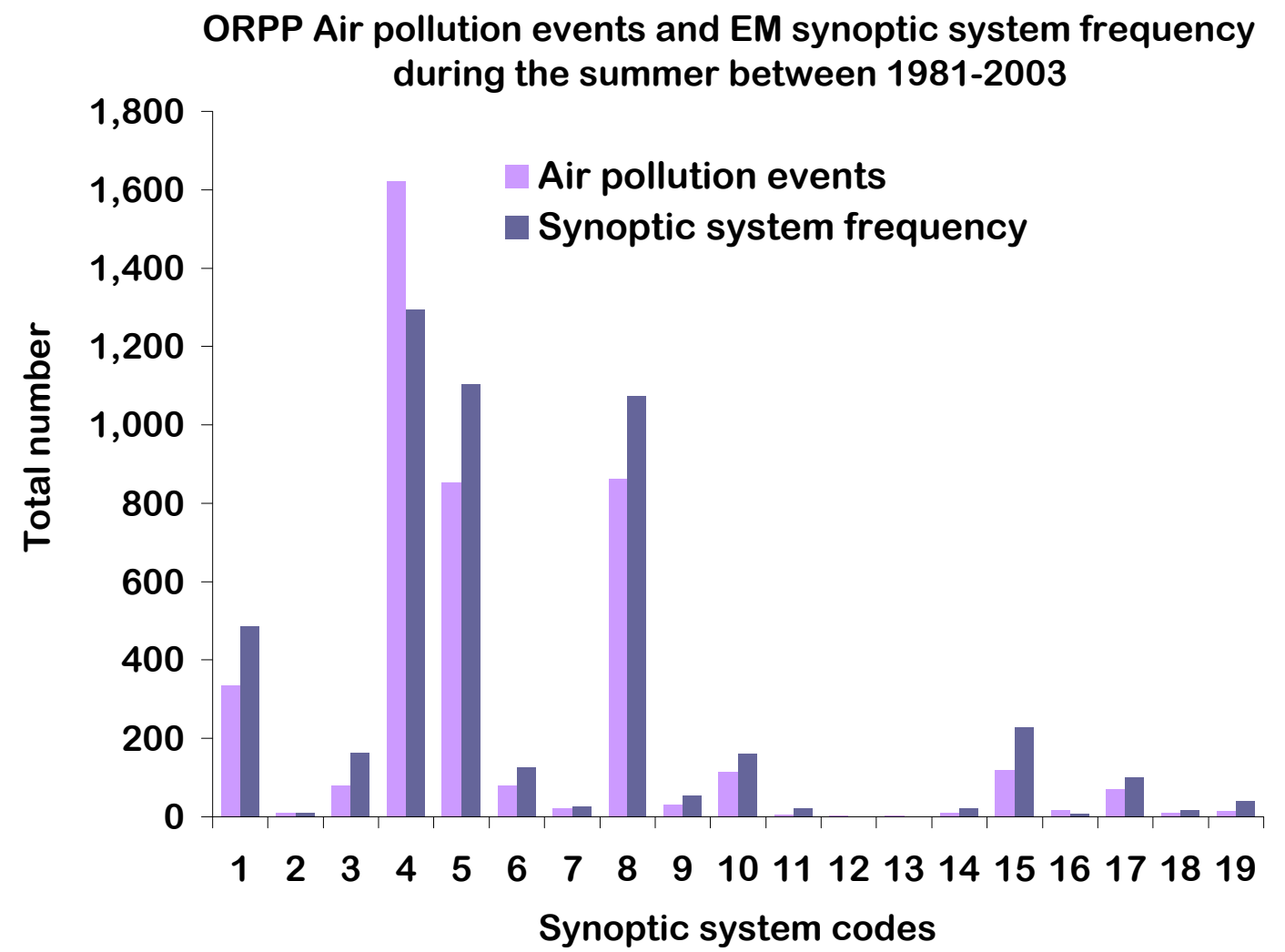

Fig. (5). Number of air pollution events originated from the ORPP during 1981-2003 for all 19 EM synoptic classes. The codes are detailed in Table 1. 
during 1981-2003 were categorized on a daily basis by EM synoptic system class codes (Table 1) [10]. Air pollution events were defined as a minimum of a half hour average of $\mathrm{SO}_{2}$ and/or $\mathrm{NO}_{\mathrm{x}}$ concentration above 70 and $125 \mathrm{ppb}$, respectively. To determine the source of the air pollution event, we followed the ATEP four basic indicators [4, 23]:

1. The ratio of $\mathrm{SO}_{2}$ to $\mathrm{NO}_{\mathrm{x}}$ concentration- indicates the type of fuel burned for various sources i.e. local industries, highways and the ORPP (being the only coal-fired power plant in area).

2. Wind direction- indicating the source location

3. Spatial distribution- following the first two indicators, ORPP air pollution is measured simultaneously at several air monitoring stations far apart but in the same wind direction, as opposite to local air pollution sources in the region which are measured only in the near-by monitoring station.

4. Meteorological conditions - such as ground-based and elevated inversions which influence differently, depending on the emission source height.

The results show that three dominant synoptic systems "controlling" the EM summer season are Persian Trough Weak (PT-W), Persian Trough Medium (PT-M) and High to the West (H-W) (Fig. 5).

Table 1. 19 Class Codes of the EM Synoptic Systems

\begin{tabular}{|c|c|c|}
\hline Code & Abbr. & English Name \\
\hline 1 & $\mathrm{RST}_{\mathrm{E}}$ & Red Sea Trough with Eastern axis \\
\hline 2 & $\mathrm{RST}_{\mathrm{W}}$ & Red Sea Trough with Western axis \\
\hline 3 & $\mathrm{RST}_{\mathrm{C}}$ & Red Sea Trough with Central axis \\
\hline 4 & PT-W & Persian Trough (Weak) \\
\hline 5 & PT-M & Persian Trough (Medium) \\
\hline 6 & PT-D & Persian Trough (Deep) \\
\hline 7 & $\mathrm{H}_{\mathrm{E}}$ & High to the East \\
\hline 8 & $\mathrm{H}_{\mathrm{W}}$ & High to the West \\
\hline 9 & $\mathrm{H}_{\mathrm{N}}$ & High to the North \\
\hline 10 & $\mathrm{H}_{\mathrm{C}}$ & High over Israel (Central) \\
\hline 11 & $\mathrm{~L}_{\mathrm{E}}-\mathrm{D}$ & Low to the East (Deep) \\
\hline 12 & $\mathrm{CL}_{\mathrm{S}}-\mathrm{D}$ & Cyprus Low to the South (Deep) \\
\hline 13 & $\mathrm{CL}_{\mathrm{S}}-\mathrm{S}$ & Cyprus Low to the South (Shallow) \\
\hline 14 & $\mathrm{CL}_{\mathrm{N}}-\mathrm{D}$ & Cyprus Low to the North (Deep) \\
\hline 15 & $\mathrm{CL}_{\mathrm{N}}-\mathrm{S}$ & Cyprus Low to the North (Deep) \\
\hline 16 & $\mathrm{~L}_{\mathrm{W}}$ & Cold Low to the West \\
\hline 17 & $\mathrm{~L}_{\mathrm{E}}-\mathrm{S}$ & Low to the East (Shallow) \\
\hline 18 & $\mathrm{SL}_{\mathrm{W}}$ & Sharav Low to the West \\
\hline 19 & $\mathrm{SL}_{\mathrm{C}}$ & Sharav Low over Israel (Central) \\
\hline
\end{tabular}

In order to specify the tropospheric conditions for the main aforementioned synoptic systems, profiles of the central coastal strip measured by the LAP-3000 profiler were investigated during the period of June-October 1997-1999 and 2002-2005. The LAP-3000 profiler is situated $3.5 \mathrm{~km}$ east to the ORPP at monitoring station Menashe (Fig. 1). The ability of the radar technology to provide useful measurements of developing convective PBL was widely studied [24- 29]. The LAP-3000 profiler is a pulsed doppler RAdio Detection And Ranging instrument (RADAR) providing wind speed (WS) and wind direction (WD) profiles. The RADAR is accompanied with a Radio Acoustic Sounding System (RASS) to provide profiles of virtual temperature $\left(\mathrm{T}_{\mathrm{v}}\right)$ data. Parameters of the profiler are given in Tables 2 and 3. In order to define the PBL height, the criteria proposed by the Israeli Meteorological Survey (IMS), were followed. These take into account the inevitable influence of the comparatively warm EM sea with regard to the cool oceans (personal communication Ilan Setter, IMS Research manager). The PBL height was defined as the height of an inversion aloft. To locate the presence of an inversion aloft, all $T_{v}$ profiles were calculated in the following manner:

1. $\mathrm{T}_{\mathrm{v}}\left(\mathrm{h}_{\mathrm{i}}\right)-\mathrm{T}_{\mathrm{v}}\left(\mathrm{h}_{\mathrm{i}-1}\right) \geq 0.5^{\circ}$

2. $\mathrm{T}_{\mathrm{v}}\left(\mathrm{h}_{\mathrm{i}+1}\right)-\mathrm{T}_{\mathrm{v}}\left(\mathrm{h}_{\mathrm{i}-1}\right) \geq 0.1^{\circ} \mathrm{C}$

where $h_{i}$ is the height of a point measured by the profiler.

Overall, a total of 802 days ( $75 \%$ of the database) were found with ORPP air pollution events and the presence of an inversion aloft.

Table 2. Description of the LAP-3000 Acoustic Radar Characteristics

\begin{tabular}{|l|l|}
\hline Frequency & $1290 \mathrm{MHz}$ \\
\hline Wavelength & $0.232 \mathrm{~m}$ \\
\hline Bandwidth & $\begin{array}{l}400 \mathrm{nS} \text { pulse (RASS), } \\
700 \mathrm{nS} \text { pulse (RADAR) }\end{array}$ \\
\hline RF Output power & $600 \mathrm{~W}$ peak \\
\hline Average power & $0.1-80 \mathrm{~W}$ \\
\hline Configuration & Three beams \\
\hline Radar beam elevation & $\begin{array}{l}\text { Beam } 1=90^{\circ}, \text { Beam } 2=74.5, \\
\text { Beam } 3=74.5,74.5^{\circ}, 74.5^{\circ}\end{array}$ \\
\hline Antenna Type & $\begin{array}{l}\text { Electrically steerable } \\
\text { micropatch phased array panel }\end{array}$ \\
\hline Antenna dimensions & 4 panel of $2.7 \mathrm{~m}^{2}$ phased array \\
\hline Altitude resolution & $\begin{array}{l}100 \mathrm{~m} \text { for the RASS, } 60 \mathrm{~m} \\
\text { for the RADAR }\end{array}$ \\
\hline Height of first range gate & $127 \mathrm{~m}$ \\
\hline Scattering media & Small scale turbulence \\
\hline RASS acoustic frequency & $2000-3000 \mathrm{~Hz}$ \\
\hline Acoustic antenna & 2 unit $1.3 \mathrm{~m}$ parabolic reflectors \\
\hline
\end{tabular}

\section{RESULTS}

All 802 days were analyzed in terms of the prevailing sea breeze front (SBF). The SBF entrance time is defined by an abrupt change of wind speed and wind direction, an increase of relative humidity and a decrease of temperature [30-33]. We investigated the SBF entrance time by the criteria proposed by Alpert and Rabinovich-Hadar [31]. 
Meteorological database was taken from four monitoring stations situated along the shore-line: Menashe, Hadera, Netanya and Maagan Michael (Fig. 1). The SB initiation time is much dictated by the land heating. Hence, the SBF times were evaluated for the three periods, June, July-August and September-October, during the period of 2003-2005 and for each synoptic system separately, i.e., PT-W, PT-M, H-W. In order to avoid cloudiness effects [28], only clear days were analyzed. Clear days were determined by the intensity of the solar radiation in the monitoring stations Hamaapil and Um El Fahem (Fig. 1). We found the SBF entrance times to be between 8:00-11:00 LST for the central coast of Israel (not shown).

Table 3. The LAP-3000 Profiler Data Collection

\begin{tabular}{|c|c|c|}
\hline Parameter & RASS & RADAR \\
\hline \hline Data & $\begin{array}{c}\text { Virtual temperature } \\
\text { (Celsius) }\end{array}$ & $\begin{array}{c}\text { Wind speed (m/s), } \\
\text { wind direction } \\
\text { (degrees) }\end{array}$ \\
\hline Time resolution & \multicolumn{2}{|c|}{ Every half hour } \\
\hline Vertical range & $127-1000 \mathrm{~m}$ & $144-1000 \mathrm{~m}$ \\
\hline Height resolution & $100 \mathrm{~m}$ & $60 \mathrm{~m}$ \\
\hline Time average & $\begin{array}{c}5 \text { min- first } 5 \text { minutes } \\
\text { of the half hour }\end{array}$ & $\begin{array}{c}25 \text { min- rest of 25 } \\
\text { minutes after the RASS } \\
\text { measurement. }\end{array}$ \\
\hline
\end{tabular}

In order to characterize the summer gradient wind, we analyzed the LAP-3000 profiles of both wind speed and wind direction (i.e., Figs. 6, 7) between July to September during 2002-2004 based on a total of 119, 65 and 38 days for the synoptic systems PT-W, PT-M, H-W, respectively. Each daily synoptic system was comprised of seven profiles based on a 3-h average for the specific day. Similar variations of wind speed and wind direction profiles were found for PT$\mathrm{W}, \mathrm{PT}-\mathrm{M}$ and $\mathrm{H}-\mathrm{W}$. The strongest average wind speed of 7 $\mathrm{m} / \mathrm{s}$ was for $\mathrm{H}-\mathrm{W}$ and $6.2 \mathrm{~m} / \mathrm{s}$ for PT-W and PT-M, were measured at 15:00 LST, 300m AGL. The profiles from sunset till dawn (18:00 to 06:00 LST) show that the average wind speed intensifies with height. Profiles indicating day time hours (09:00-15:00 LST) show just the opposite. This phenomenon is explained by Stull [20] with the production term in the simplified velocity variance budget equation. During the night hours, the decreasing wind speed in the lower levels of the troposphere ( beneath 500m AGL) combined with the presence of a nocturnal inversion, prevent the momentum flux (of wind speed) to move downward, and, therefore, the wind speed at the upper level intensifies. The division of the PBL into two layers, approximately above and beneath $500 \mathrm{~m}$ AGL, is associated with the depth of the SBF.

Tracking the PBL average wind direction profiles, we found veering of the winds to the North with height, as the friction weakens (i.e., Fig. 7). Between 03:00-06:00 LST the wind direction in the lowest layer (beneath $500 \mathrm{~m}$ ) turns east due to the influence of the land breeze. The land breeze is prominent in ground level measurements, whereas here, the lowest measurement of the profiler starts at 144m AGL. Therefore, we can only observe the influence of the top of the land breeze layer. After the SBF enters (10:00 LST) the SB dominates the near-surface atmospheric profiles. The SBF height of influence (starting from 12:00 to 18:00 LST) is indicated at about $500 \mathrm{~m}$ as a set of similar profiles.

Knowing the synoptic wind vector variations and the SBF entrance time, we evaluated the diurnal variation of the PBL based on the LAP-3000 data base for wind speed, wind

Wind speed profiles of 119 PT-W days between July-September 2002-2004

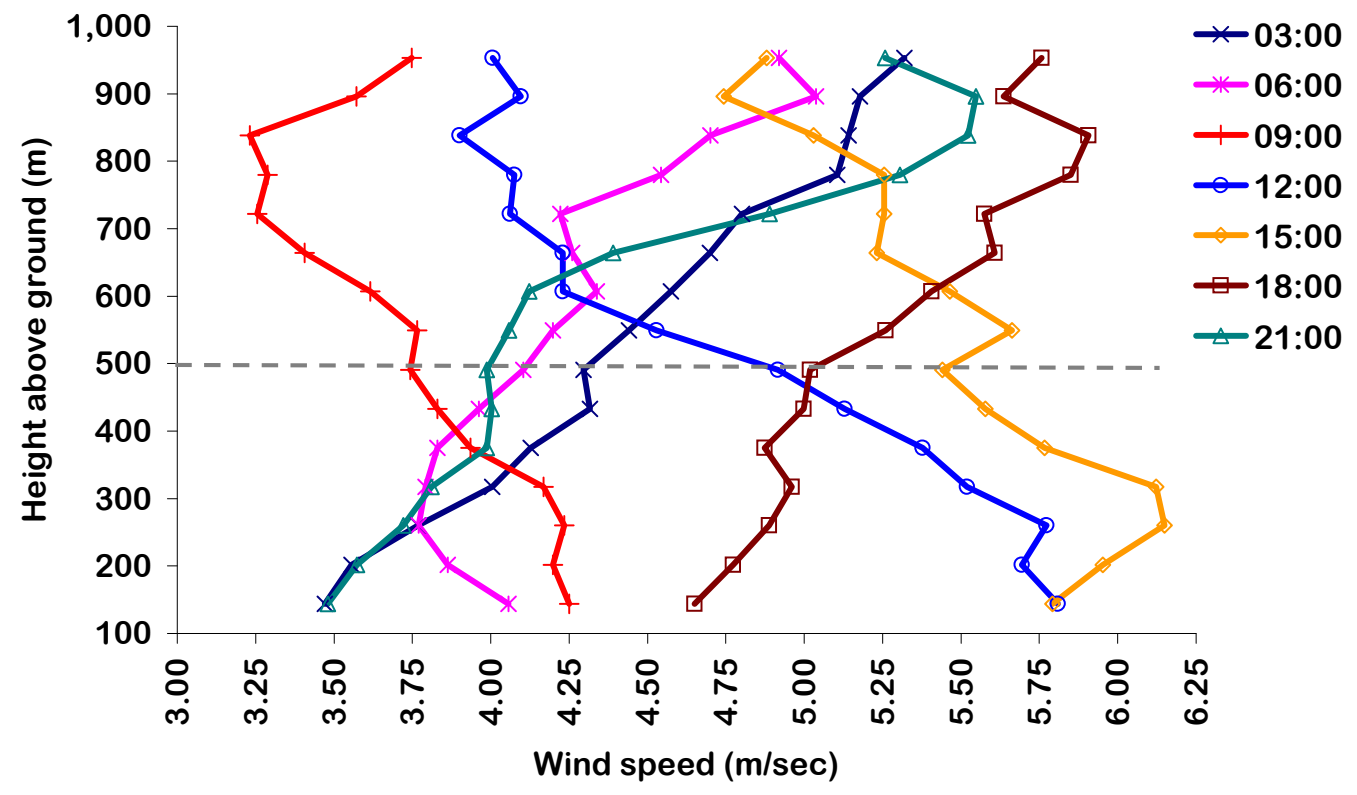

Fig. (6). 119 days of wind speed profile intensities, for synoptic system PT-W measured by the LAP-3000 profiler, during July-September 2002-2004. The profiles were averaged for every three hours, between 03:00-21:00 LST. Time indicates the ending of the 3-h period, for instance, 03:00 averages all (6) profiles during 00:00-03:00. Dashed line indicates the average depth of the SBF, see text. 
Wind direction profiles of 65 PT-M days between July-September 2002-2004

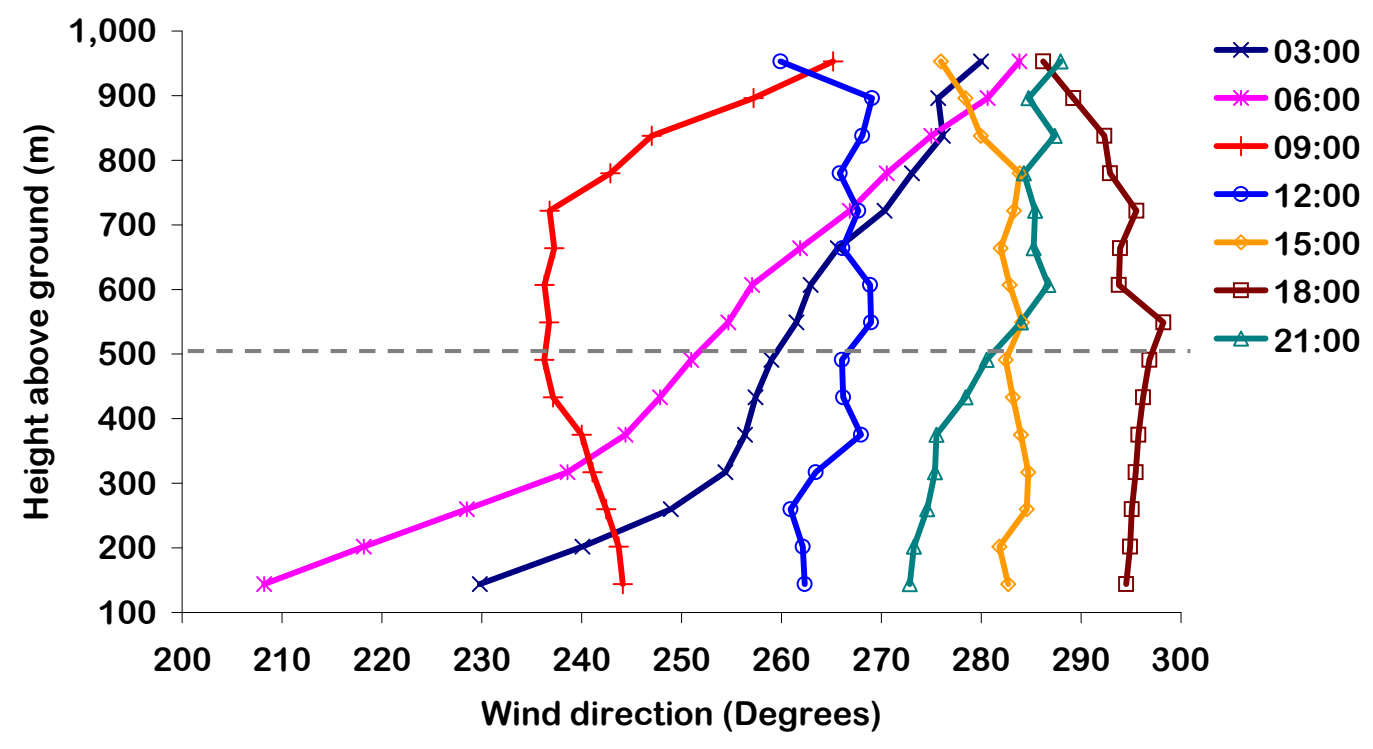

Fig. (7). Same as Fig. (6) but for 65 PT-M synoptic days with their respective wind direction profiles.

direction and virtual temperature profiles. Each of the 802 days discussed above, is comprised of 48 profiles. The profiles were examined by the criteria given in section 2 , in order to define the PBL height. The average wind speed of the PBL for each synoptic system was evaluated by an arithmetic average of all pertinent profiles. Wind direction analysis was done in the same manner but with a vector average.
The acoustic radar enables to identify the SBF time. The SB entrance time (approximately 10:00 LST) is emphasized by veering (clockwise) of the wind to the west (Fig. 10), followed by the intensification of the PBL average wind speed (Fig. 8). Southwesterly winds within the inflated PBL (Fig. 10) lead to lower air pollution events measured north east to the ORPP. Later on, between 14:00-18:00 LST, the SB cool marine air manifestation leads to subsidence (Fig.

\section{PBL average wind speed for synoptic systems H-W, PT-M, PT-W between June - October, 1997-1999, 2002-2005}

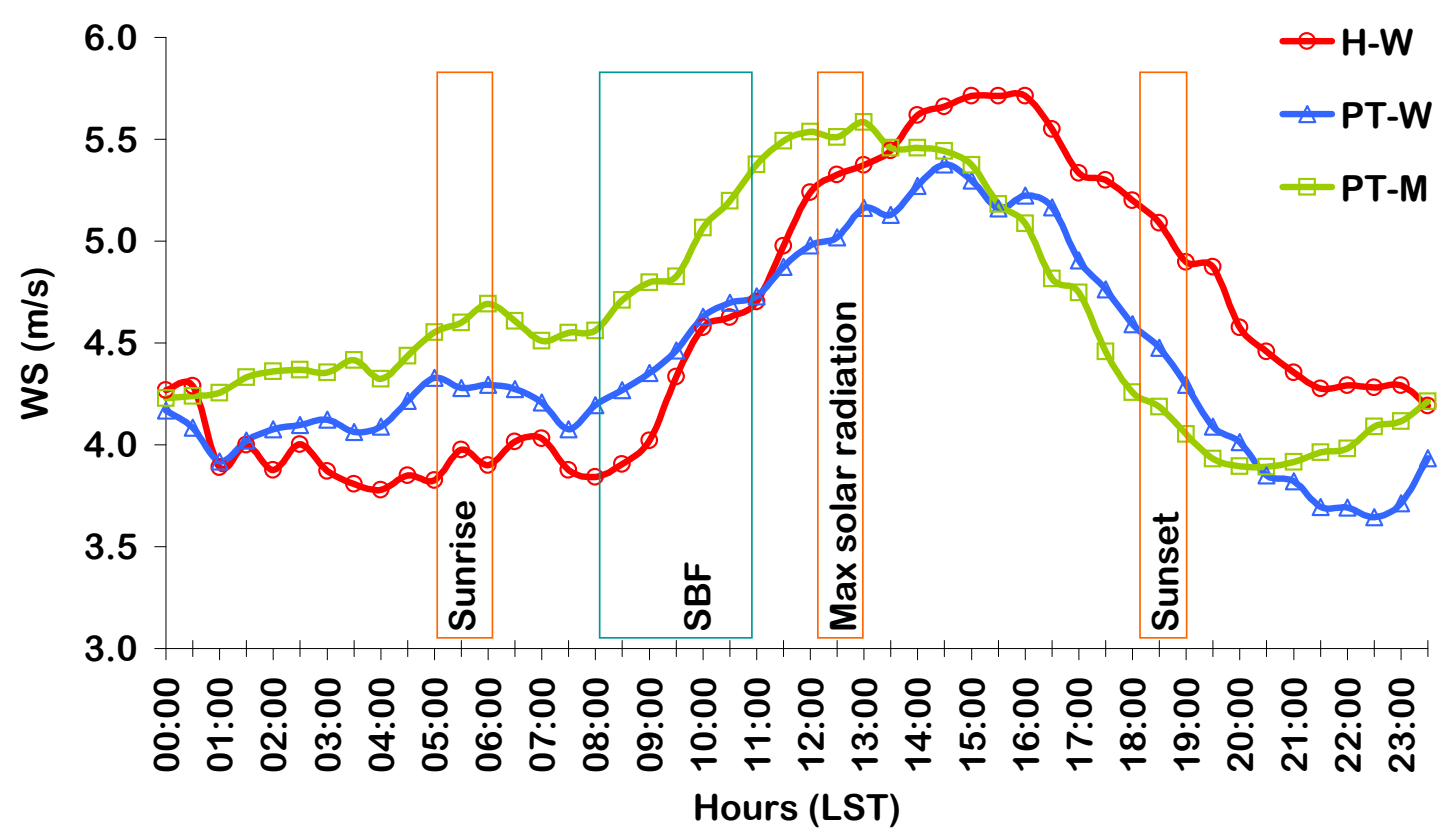

Fig. (8). PBL averaged wind speed diurnal variations in days with an inversion aloft for the following three synoptic systems, PT-W, PT-M and H-W. A total of three profiles based on 347 days for PT-W, 232 days for PT-M, and 198 days for H-W, during June-October 1997-1999, 2002-2005. The profiles were measured by the LAP-3000 profiler (Sec. 2). Also indicated are the time period of sunrise and sunset, the period of maximum solar radiation and the SBF times of entrance and weakening. See text for the method of calculation. 
9). Once the SB and the synoptic winds are approximately parallel (Table 4), the average PBL wind intensifies up to 5$6 \mathrm{~m} / \mathrm{s}$ (Fig. 8) and partially suppressing the buoyancy force of the PBL thermals. The combination of a lowered PBL and prevailing westerly winds (Fig. 10) both lead to the highest air pollution events measured west of the ORPP. As the SB continues its clockwise circulation towards the south it decelerates and the PBL average wind speed weakens [33]. As a result, the PBL inflates, and lower air pollution concentrations are measured North West to the ORPP. After sunset, the formation of ground level inversion withholds the convection of air pollution near the surface. ORPP air pollution is again measured following the next day sunrise and another diurnal cycle begins.

\section{CONCLUSIONS}

The highest and most frequent air pollution events, originated from the "Orot -Rabin" coal-fired power plant

\section{PBL average Height for synoptic systems H-W, PT-M, PT-W between June - October, 1997-1999, 2002-2005}

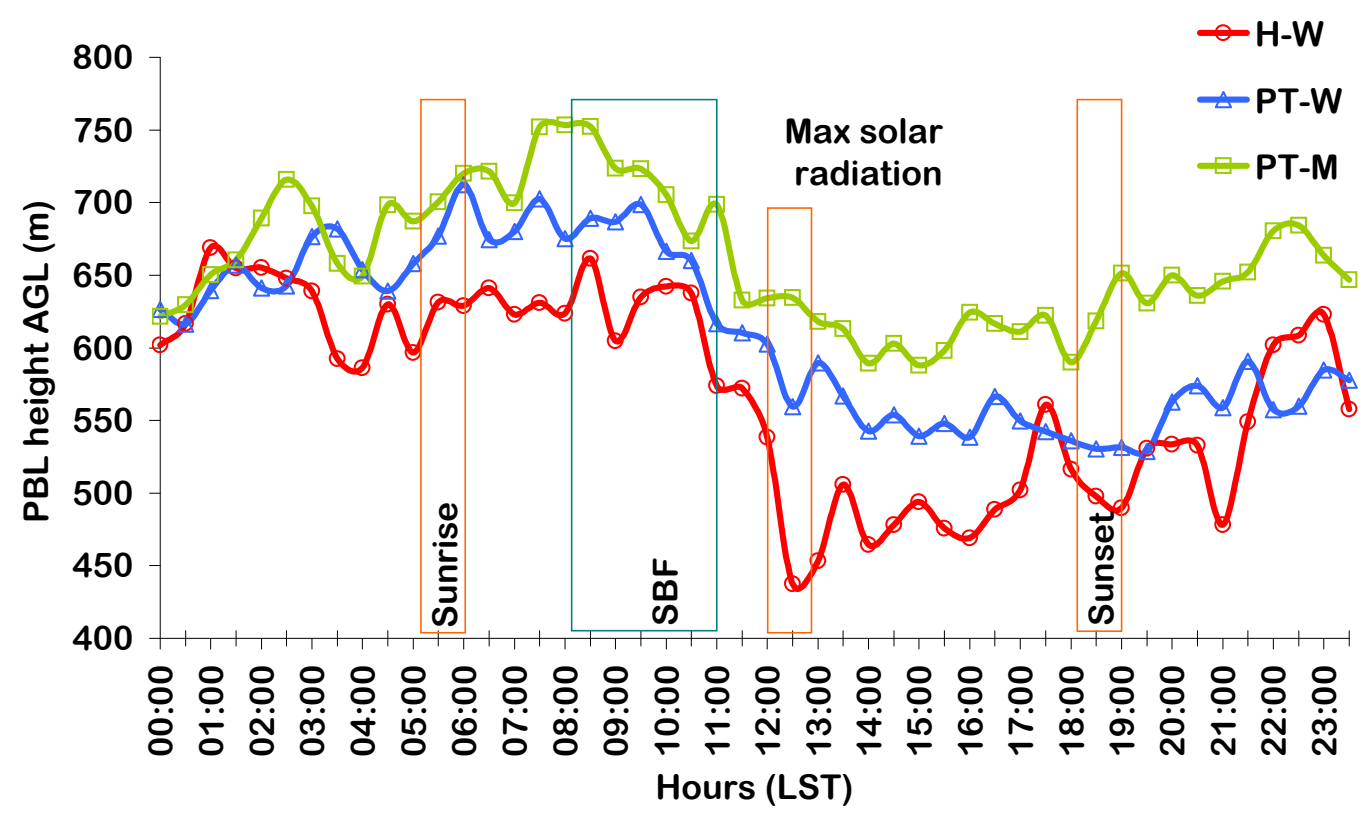

Fig. (9). As in Fig. (8) but for PBL height.

\section{PBL average wind direction for synoptic systems H-W, PT-M, PT-W between June - October, 1997-1999, 2002-2005}

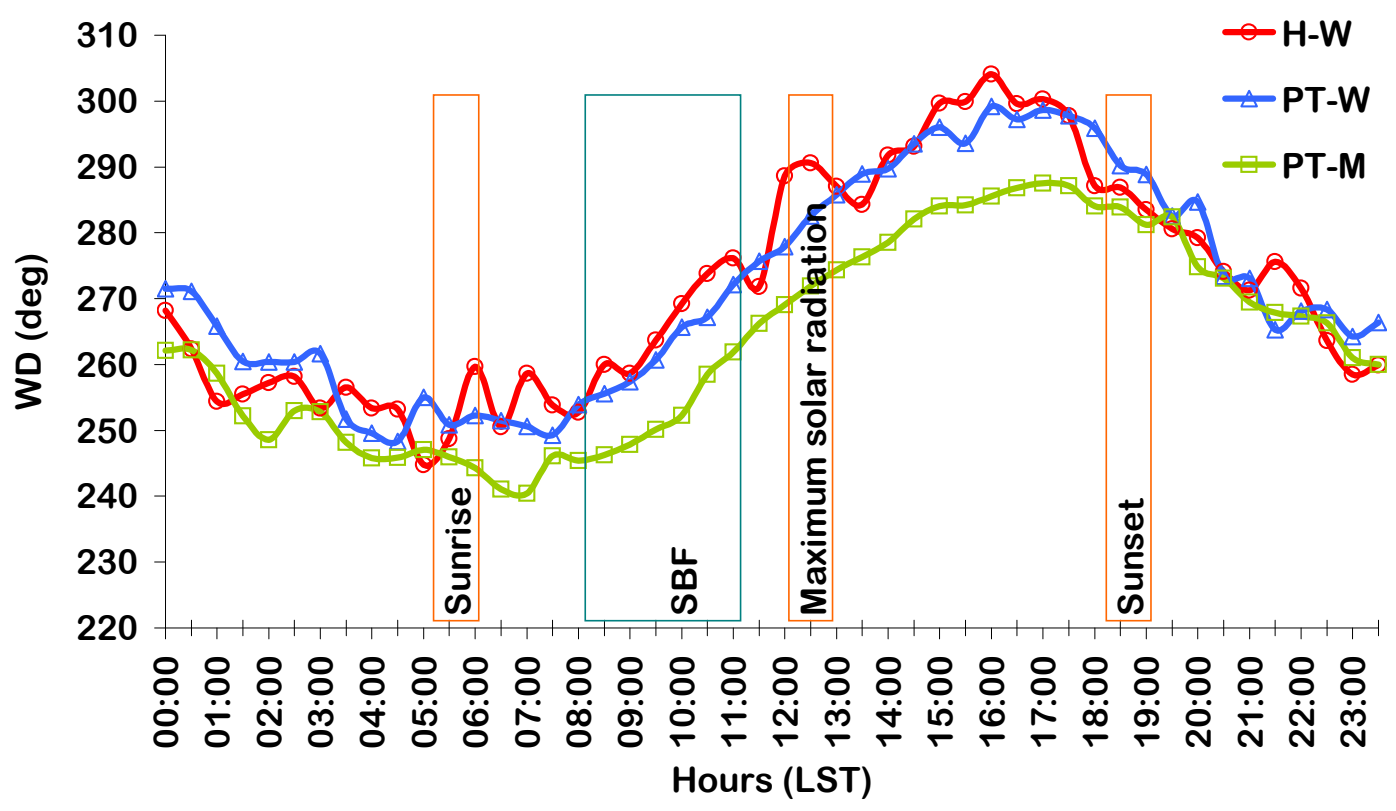

Fig. (10). As in Fig. (8) but for wind direction. 
(ORPP), during 12:00-15:00 $\mathrm{h}$ are measured in the summer season during the months of June- September. The Israeli summer is defined by three main synoptic systems- Persian Trough Weak (PT-W), Persian Trough Medium (PT-M) and High to the West (H-W), followed by a semi-permanent inversion aloft. Analysis of the LAP-3000 profiles manifests the dominant role of the sea breeze (SB) in the diurnal cycle of the spatial and temporal ORPP air pollution dispersion. A Total number of 4,248 air-pollution events were analyzed. Tracking down the diurnal intensification (between 08:00-15:00 h) and declaration (between 16:00 23:00 h) of the wind speed, the clockwise circulation of the wind direction and the gradual drop of the planetary boundary layer (PBL) height of 150m between $0800-14: 00$ $\mathrm{h}$, elucidates the phenomena of most frequent and consistent air pollution events in the afternoon hours (12:00- 15:00 h) measured east to the ORPP, which are attributed to the subsidence of the PBL as the westerly SB winds gain control.

Table 4. Wind Direction at Time of Maximum PBL Average Wind Speed for Synoptic Systems PT-M, PT-M, HW During June-October 1997-1999, 2002-2005

\begin{tabular}{|c|c|c|c|}
\hline H-W & PT-W & PT-M & Synoptic System \\
\hline \hline $16: 00$ & $14: 30$ & $13: 00$ & Time of maximum PBL wind speed (Fig. 8) \\
\hline $290^{\circ}$ & $290^{\circ}$ & $280^{\circ}$ & Sea breeze wind direction ${ }^{\mathrm{a}}$ \\
\hline $6^{\circ}$ & $290^{\circ}$ & $270^{\circ}$ & Synoptic system wind direction $^{\mathrm{b}}$ \\
\hline $305^{\circ}$ & $295^{\circ}$ & $275^{\circ}$ & PBL average wind direction (Fig. 10) \\
\hline
\end{tabular}

\section{DISCUSSION}

This research emphasizes the importance of the understanding well the role of the atmospheric dynamics in the mesoscale and its interaction with the synoptics, on the air pollution dispersion. The steady synoptic condition dominating the summer of the research zone enables us to clearly define the wind circulation pattern, and calculate the sea breeze (SB) front depth diurnal variations of the order of $500 \mathrm{~m}$. On the one hand, the strength of SB during the daytime spawns higher ground level air pollution from tall stacks. On the other, once the SB turns into land breeze, and inversion aloft is reinforced by ground inversion, weak easterly winds slowly cover the region with a blanket of concentrated ground level air pollution from different sources such as agriculture burning, vehicle emissions, local industries etc. This result with odorous air pollution complains from wide vicinity. In future, we recommend expanding such research to a seasonly investigation of the meso scale atmospheric conditions, for a better understanding of the overall air pollution dispersion from various regional dominate sources. Overall, atmospheric dynamics is yet to be delivered to decision makers as environmental regulations are tightened.

\section{ACKNOWLEDGEMENTS}

On the last steps, the work was supported by the ministry of Environment of Israel. Partial support was given by the EU-CIRCLE and BMBF/MOS GLOWA-JR projects.
Special thanks to Y. Lakretz (ATEP) and Dr. Setter (IMS) for their assistance.

\section{CONFLICT OF INTEREST}

None declared.

\section{REFERENCES}

[1] Dayan U, Shenhav R, Graber M. The Spatial and temporal behavior of the mixed layer in Israel. J Appl Meteorol 1988; 27 : 1382- 94.

[2] Dayan U, Rodnizki J. The temporal behavior of the atmospheric boundary layer in Israel. J Appl Meteorol 1999; 38: 830-6.

[3] Dayan U, Lifshitz-Goldreich B, Pick K. Spatial and structural variation of the atmospheric boundary layer during summer in Israel-profiler and rawinsonde measurements. J Appl Meteorol 2002; 41: 447-57.

[4] Koch J, Dayan U. A synoptic analysis of the meteorological conditions affecting dispersion of pollutants emitted from tall stacks in the coastal plain of Israel. Atmos Environ 1992; 26A(14): 2537-43.

[5] Sharf G, Peleg M, Livnat M, Luria M. Plume rise measurements from large point sources in Israel. Atmos Environ 1993; 27A(11): 1657-63.

[6] Alpert P, Abramsky R, Neeman BU. The prevailing summer synoptic system in Israel- subtropical high, not Persian trough. Isr J Earth Sci 1991; 39: 93-102.

[7] Barkan J, Felix Y. Observations of the diurnal oscillation of the inversion over the Israeli coast. Bound-Layer Meteorol 1993; 62: 393-409.

[8] Felix Y. A numerical model for estimation of the diurnal fluctuation of the inversion height due to a sea breeze. BoundLayer Meteorol 1993; 62: 151-61.

[9] Tokar Y, Goldstein J, Levin Z, Alpert P. The use of a mesogamma scale model for evaluation of pollution concentration over an industrial region in Israel (Hadera). Bound-Layer Meteorol 1991; 62: 185-93.

[10] Alpert P, Osetinsky I, Ziv B, Shafir H. Semi-objective classification for daily synoptic systems; application to the eastern Mediterranean climate change. Int J Climatol 2004; 24: 1001-11.

[11] Bitan A, Saaroni H. The horizontal and vertical extension of the Persian Gulf pressure trough. Int J Climatol 1992; 12: 733-47.

[12] Osetinsky I."Climate changes aver the E.mediterranian-Asynoptis system classification approach". Geophys Planet Sci; Tel Aviv University, Tel Aviv, Israel 2006.

[13] Alpert P, Leiman R. Investigation of the planetary boundary layer height variations over complex terrain. Bound-Layer Meteorol 1993; 62:129-42.

[14] Challa VS, Indracanti J, Rabarison MK, et al. A simulation study of mesoscale coastal circulations in Mississippi Gulf coast. Atmos Res 2009; 91: 9-25.

[15] Chen MJ, Oke RT. Mixed layer heat advection and entrainment during the sea breeze. Bound-Layer Meteorol 1994; 68: 139-58.

[16] Crosman TE, Horel DJ. Sea and lake breezes a review of numerical studies. Bound-Layer Meteorol 2010; 137: 1-29.

[17] Edinger JG. Modification of the marine layer over coastal southern California. J Appl Meteorol 1963; 2(6): 706-12.

[18] Ludwing FL. A review of coastal zone meteorological processes important to the modeling of air pollution. Proc $14^{\text {th }}$ Int Tech Meeting on air pollution modeling and it's application. Copehagen, Denmark, NATO Committee on Challenges of Modern Society 1983; pp. 225-57.

[19] Nielsen-Gammon JW. Initial modeling of the August 2000 Houston- Galveston ozone episode, report to the technical analysis division, Texas natural resource conservation commission. College Station, TX, USA 2001.

[20] Stull RB. An introduction to boundary layer meteorology; Dordrecht. The Netherlands: Kluwer Academic Publishers 1988.

[21] Stunder M, Sethuraman S. A comparative evaluation of the coastal internal boundary layer height equations. Bound-Layer Meteorol 1985; 32: 177- 204 .

[22] Kalmikov A. Generation mechanisms of elevated temperature inversions in the eastern mediterranaen. Geophysics \& Planetary Sciences: Tel Aviv University, Tel Aviv, Israel, 2006. 
[23] Nirel R, Dayan U. On the ratio of Sulfur Dioxide to Nitrogen Oxides as an indicators of air pollution sources. J Appl Meteorol 2001; 40: 1209-22.

[24] Frisch AS, Clifford SF. A study of convection capped by a stable layer using Doppler radar and acoustic echo sounders. J Atmos Sci 1974; 31: 1622-28.

[25] Gossard EE, Gaynor JE, Zamora RJ, Neff WD. Fine structure of elevated stable layers observed by sounder and in situ tower sensors. J Atmos Sci 1985; 42: 2156-69.

[26] Marsik FJ, Fischer KW, McDonald TD, Samson PJ. Comparison of methods for estimating mixing height used during the 1992 Atlanta field Intensive. J Appl Meteorol 1995; 34: 1802-14.

[27] Martner BE, Wuertz DB, Stankov BB, et al. An evaluation of wind profiler, RASS, and microwave radiometer performance. Bull Am Meteorol Soc 1993; 74: 599-613.
[28] Noonkester VR. The evolution of the clear air convective layer revealed by seface-based remote sensors. J Appl Meteorol 1976; 15: 594- 606 .

[29] Puygrenier V. Investigation on the fine structure of sea-breeze during ESCOMPTE experiment. Atmos Res 2005; 74: 329-53.

[30] Alpert P, Cohen A, Neumann J, Doron E. A model simulation of the summer circulation from the eastern Mediterranean past Lake Kineret in the Jordan valley. Mon Weather Rev 1982; 116: 204761.

[31] Alpert P, Rabinovich-Hadar M. Pre- and post- sea-breeze frontal lines: a meso $\gamma$ scale analysis over south Israel. J Atmos Sci 2003; 60: 2994- 3008 .

[32] Atkinson BW. Meso-scale atmospheric circulation. New York, USA: Academic Press 1981.

[33] Simpson JE. Sea-breeze and local winds; United Kingdom. Cambridge University Press 1994.

Received: October 25, 2011

Revised: November 17, 2011

Accepted: November 18, 2011

(C) Uzan and Alpert; Licensee Bentham Open.

This is an open access article licensed under the terms of the Creative Commons Attribution Non-Commercial License (http: //creativecommons.org/licenses/by$\mathrm{nc} / 3.0 /$ ) which permits unrestricted, non-commercial use, distribution and reproduction in any medium, provided the work is properly cited. 